\title{
Immune response of macrophages from young and aged mice to the oral pathogenic bacterium Porphyromonas gingivalis
}

\author{
Yazdani B Shaik-Dasthagirisaheb ${ }^{1}$, Alpdogan Kantarci², Frank C Gibson II $^{{ }^{* *}}$
}

\begin{abstract}
Periodontal disease is a chronic inflammatory gum disease that in severe cases leads to tooth loss. Porphyromonas gingivalis $(\mathrm{Pg})$ is a bacterium closely associated with generalized forms of periodontal disease. Clinical onset of generalized periodontal disease commonly presents in individuals over the age of 40 . Little is known regarding the effect of aging on inflammation associated with periodontal disease. In the present study we examined the immune response of bone marrow derived macrophages (BMM) from young (2-months) and aged (1-year and 2years) mice to $\mathrm{Pg}$ strain 381. Pg induced robust expression of cytokines; tumor necrosis factor (TNF)- $\alpha$, interleukin (IL)-6, and IL-10, chemokines; neutrophil chemoattractant protein (KC), macrophage colony stimulating factor (MCP)-1, macrophage inflammatory protein (MIP)-1 $\alpha$ and regulated upon activation normal T cell expressed and secreted (RANTES), as well as nitric oxide (NO, measured as nitrite), and prostaglandin E2 (PGE2) from BMM of young mice. BMM from the 2-year age group produced significantly less TNF- $\alpha, \mathrm{LL}-6$ and NO in response to Pg as compared with BMM from 2-months and 1-year of age. We did not observe any difference in the levels of IL-1 $1 \beta$, IL-10 and PGE2 produced by BMM in response to Pg. BMM from 2-months and 1-year of age produced similar levels of all chemokines measured with the exception of MCP-1, which was reduced in BMM from 1-year of age. BMM from the 2-year group produced significantly less MCP-1 and MIP-1 $\alpha$ compared with 2-months and 1-year age groups. No difference in RANTES production was observed between age groups. Employing a Pg attenuated mutant, deficient in major fimbriae (Pg DPG3), we observed reduced ability of the mutant to stimulate inflammatory mediator expression from BMMs as compared to Pg 381, irrespective of age. Taken together these results support senescence as an important facet of the reduced immunological response observed by BMM of aged host to the periodontal pathogen $\mathrm{Pg}$.
\end{abstract}

\section{Background}

As humans age, they become more susceptible to a variety of infections including those of the lung, urinary tract, and skin [1]. This increase in infection results in concomitant increase in morbidity and mortality for elderly individuals [1]. The mechanisms underlying agedependent increase in susceptibility to infection are complex, though decline in immune function and immune senescence is thought to play a central role [2]. Age-related changes in immune fitness have been identified in both the adaptive and innate arms. Effects associated with aging on adaptive immunity include

\footnotetext{
* Correspondence: fgibson@bu.edu

'Department of Medicine, Section of Infectious Diseases, Boston University

School of Medicine, Boston, Massachusetts 02118, USA

Full list of author information is available at the end of the article
}

diminished capacity of cells to present antigen, as well as reduced capacity to generate antigen-specific $T$ and $B$ cells $[3,4]$. Changes in innate immune response include capacity to recognize and respond to pathogens, which may be in part as a result of reduced expression of cell surface receptors, such as the Toll-like receptors (TLRs) [5]. TLRs are a family of receptors that bind conserved microbial structures shared by large groups of pathogens, termed pathogen-associated molecular patterns. Ligation of these receptors with specific pathogen derived antigens initiates intracellular signaling that culminates in coordinated expression of genes that encode molecules such as cytokines and chemokines [6]. Cytokines and chemokines serve diverse roles in many host functions including cell activation, immune function, and communication as well as cell recruitment.

\section{C) Biomed Central}


Aberrant production of cytokines and chemokines has been observed in aged individuals as compared with young [7].

Periodontal disease is a common chronic oral inflammatory disease [8]. Although complex in pathogenesis, it is commonly thought that erosion of the soft and hard tissue supporting teeth results from bacteria-elicited inflammation. Among the various bacterial species associated with the development of periodontitis, Porphyromonas gingivalis (Pg), a Gram-negative anaerobic bacterium suspected to be one of the most important causative agents of the chronic form of this disease $[9,10]$. Pg produces several virulence factors, including outer membrane vesicles, adhesins, lipopolysaccharide (LPS), hemolysins and proteinases [11-15]. It is established that the innate immune response to this organism and its antigens plays a predominant role in periodontal disease pathogenesis [16]. TLRs have been shown to participate in the recognition of Pg components such as LPS, and fimbriae, which in turn leads to aspects of periodontal disease including cytokine, chemokine production, and oral bone loss $[13,15,17]$. Epidemiological data from humans has shown $\mathrm{Pg}$ in the oral cavity of young adults (20-30 years of age), however clinical onset of periodontal disease is not commonly identified until the 3-4 decade of life. Susceptibility to this disease increases with age $[18,19]$. Despite evidence supporting early acquisition of $\mathrm{Pg}$ and other periodontal pathogens to the oral microflora [18], why adults show onset of periodontal disease later in life is not clearly understood. Employing a macrophage challenge model, in the present study we were interested to determine if the innate immune response to $\mathrm{Pg}$ is affected by host age. Our observations identify that BMM from aged mice respond to Pg challenge with reduction in key sets of immune mediators, as compared with BMM obtained from young animals. Data from these studies support that immune senescence may play an important role in the age-dependent pathogenesis of periodontal disease.

\section{Experimental system}

To address the effect of aging on immunological response to periodontal pathogens, we employed an in vitro macrophage model and cultured these cells with wild type Porphyromonas gingivalis strain 381 (Pg 381), a laboratory strain [20] originally isolated from a patient with chronic periodontitis [21]. Mice were purchased from Jackson Laboratory (Bar Harbor, ME) and aged in accordance with Boston University Institutional Animal Care and Use Committee approvals. Bone marrow derived macrophages (BMM) were generated from young (2-months) and aged (1-year and 2-year) C57BL6 mice. Bone marrow cells were harvested following sacrifice, and differentiated to BMM for 7 days in RPMI
1640 supplemented with $20 \%$ L-929 cell culture conditioned media as source of macrophage colony stimulating factor (M-CSF) [22]. Adhered cells were collected, placed into wells of tissue culture plates at $5 \times$ $10^{5}$ cells $/ \mathrm{mL}$, and were challenged with anaerobically grown Pg organisms at multiplicity of infection (MOI) of 100 as previously described [20]. BMM were also cultured with a genetically engineered major fimbriae-deficient mutant, Pg DPG3, characterized both in vitro and in vivo to be virulence attenuated [23-25]. Culture supernatant fluids were collected from unchallenged and Pg-challenged BMM after $24 \mathrm{~h}$ of co-culture and the levels of cytokines, chemokines, nitric oxide (measured as nitrite) and PGE2 were determined.

\section{Results}

Cytokines are important signaling molecules induced from immune cells in response to microbial infection. Elevated levels of both pro- and anti-inflammatory cytokines have been detected in tissues from patients with periodontitis [26,27]. Experimental studies support that periodontal pathogens such as $\mathrm{Pg}$ and its antigens are capable of driving cytokine production from immune cells [28-30]. To determine the levels of cytokines and chemokines in the culture supernatant fluids from BMM-Pg co-cultures, we used the xMAP multiplex immuno assays. Culture supernatant fluids from unchallenged and Pg challenged BMM were added to wells (50 $\mu \mathrm{L} /$ well) of 96 well filter bottom plates and incubated with microsphere beads coated with anti-mouse antibodies against studied targets according to manufacturer's instructions (Invitrogen, Carlsbad, CA). Plates were read with a Luminex 200 multi laser scanner (Luminex, Austin, TX), and data analysis was performed using Bio-Plex Manager software (Bio-Rad, Hercules, CA). The concentration of each analyte was calculated using assay standard curves. We observed that cell culture supernatant fluids from Pg-challenged BMM responded with robust induction of both pro-inflammatory and anti-inflammatory cytokines (Figure 1). Supernatant fluid levels of the pro-inflammatory cytokines TNF- $\alpha$ and IL- 6 were similar between BMM of 2months and 1-year aged mice. BMM from 2-year aged mice exhibited attenuated TNF- $\alpha$ and IL- 6 production when compared to the 2-months and 1-year age groups (Figure $1 \mathrm{~A}$ and $1 \mathrm{C}$ ). Focusing on another pro-inflammatory cytokine, IL-1 $\beta$, we observed slightly elevated IL-1 $\beta$ in culture supernatant fluids of BMM cultured with Pg; however, no difference was observed in the IL-1 $\beta$ response to $\mathrm{Pg}$ between the age groups (Figure $1 \mathrm{~B}$ ). Next we measured levels of the immunoregulatory/antiinflammatory cytokine IL-10, a key molecule associated with periodontal disease and host response to $\mathrm{Pg}$ $[31,32]$. We observed that Pg elicited a strong IL-10 


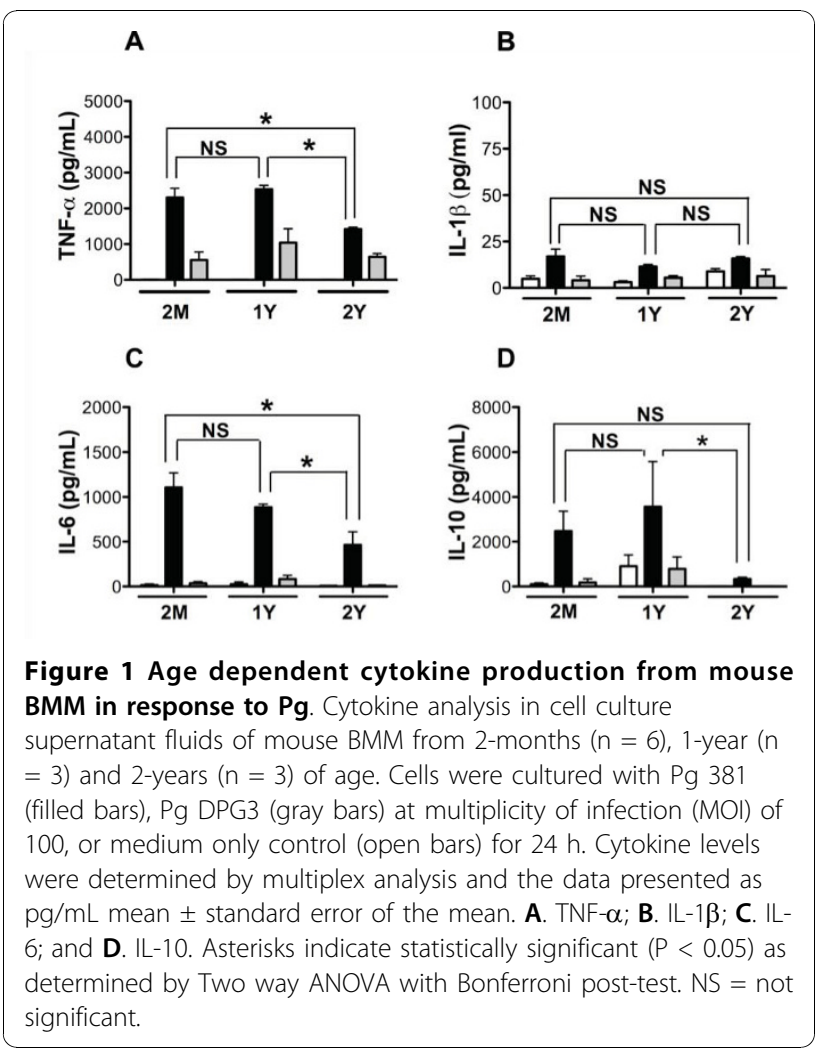

response from BMM. Furthermore, the levels of IL-10 were significantly reduced in culture supernatant fluids of BMM from 2-year aged mice as compared to BMM from the 1-year age group (Figure 1D). No statistically significant differences in IL-10 were observed between the 2-months and 2-year age groups, although trend existed (Figure 1D). These cytokine data support that BMM from aged mice exhibited reduced ability to produce both pro-inflammatory and anti-inflammatory cytokines in response to Pg 381 exposure.

Chemokines are a large family of host secreted glycoproteins that possess roles in a myriad of host functions including recruitment of specific sets of immune cells to site of infection [33]. In periodontal disease, chemokines have been detected in tissues of patients, and support chemotaxis and activation of inflammatory cells that comprise the periodontal lesion $[34,35]$. Based on the clear association between cellular infiltrate and periodontal disease, we measured the levels of chemokines; KC, MCP-1, MIP- $1 \alpha$, and RANTES produced by BMM in response to $\mathrm{Pg}$ challenge to determine if aging affects the ability of macrophages to produce these chemokines. BMM responded to Pg challenge with robust expression of all chemokines measured regardless of age. We observed that BMM from young mice expressed high levels of MCP-1 in response to Pg, while levels from the 1 -year group were significantly reduced (Figure $2 \mathrm{~B}$ ).
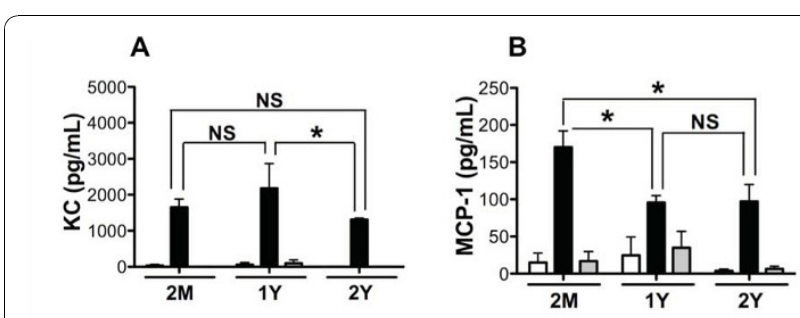

C

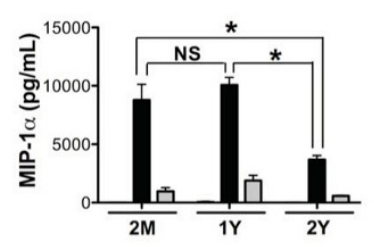

D

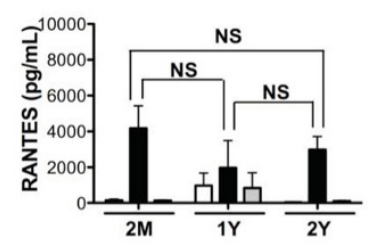

Figure 2 Chemokine response of young and aged mouse BMM to $\mathbf{P g}$. Chemokine levels in cell culture supernatant fluids of mouse BMM from 2-months $(n=6)$, 1-year $(n=3)$ and 2-years $(n=3)$ of age. BMM were challenged with Pg 381 (filled bars), Pg DPG3 (gray bars) at multiplicity of infection (MOI) of 100 , or medium only control (open bars) for $24 \mathrm{~h}$. Chemokine levels were determined by multiplex analysis and the data presented as $\mathrm{pg} / \mathrm{mL}$ mean \pm standard error of the mean. A. KC; B. MCP-1; C. MIP-1 $\alpha$; and D. RANTES. Asterisks indicate statistically significant $(P<0.05)$ as determined by Two way ANOVA with Bonferroni post-test analysis. NS = not significant.

No other significant differences were observed in chemokine expression between 2-month and 1-year of age (Figure 2). BMM from 2-year group showed significant reduction in the levels of MIP- $1 \alpha$ in response to $\mathrm{Pg}$ challenge compared with 2-months age group (Figure $2 \mathrm{C}$ ), whereas levels of $\mathrm{KC}$ significantly reduced in BMM from 2-year group compared with 1-year age group (Figure $2 \mathrm{~A}$ ). Although trends appeared to exist, RANTES expression following Pg 381 challenge was similar between age groups (Figure 2D). This observed profile of chemokine expression complements our cytokine expression data indicating that BMM from aged hosts display attenuation in the levels of innate immune mediators to Pg 381 and the magnitude of this reduced ability to produce chemokines increases with age.

Next we examined the levels of nitric oxide (NO) in culture supernatant fluids from BMM challenged in vitro with Pg, measured as total nitrite by Griess reaction [36]. Inflammatory cells such as macrophages produce NO in response to bacterial challenge. The enzyme inducible nitric oxide synthase (iNOS) is responsible for $\mathrm{NO}$ production. Loss in the ability to fully express $\mathrm{NO}$ by alveolar macrophages in response to Listeria monocytogenies has been linked to aging, and likely contributes to host response to infection [37]. NO possesses bactericidal activity against a wide range of bacteria including 
Pg $[38,39]$. Mice deficient in the enzyme iNOS show impaired ability to clear Pg [40,41]. Also mice deficient in iNOS production showed increased tissue damage with Pg challenge [42]. Thus, we were interested to determine if age is associated with macrophage ability to produce $\mathrm{NO}$ in response to $\mathrm{Pg}$. Measuring the stable product nitrite as a proxy for $\mathrm{NO}$ expression, we observed that BMM cultured with Pg produced high levels of $\mathrm{NO}$ as compared with unchallenged control cells. NO levels in culture supernatant fluids were similar between 2-month and 1-year BMM; however, BMM from 2-year age group presented with significantly reduced NO levels in comparison to 2-months and 1year age groups (Figure 3). Our results suggest that BMM from aged mice (2-years of age) exhibit attenuated capacity to produce $\mathrm{NO}$ as compared with BMM from young mice in response to the periodontal pathogen Pg 381.

PGE2 is an immunomodulatory product of the arachidonic acid pathway that is secreted by immune cells in response to microbial challenge. Prostaglandins including PGE2 possess both pro- and anti-inflammatory activities, and can affect bone metabolism [43]. Elevated PGE2 levels have been detected in periodontal disease and are thought to play a key role in the progression of this disease [44]. To determine if the magnitude of prostaglandin production by BMM in response to Pg challenge is influenced by aging, we measured PGE2 levels in the culture supernatant fluids of BMM cultured with Pg by ELISA (R\&D Systems, Minneapolis, MN). Pg

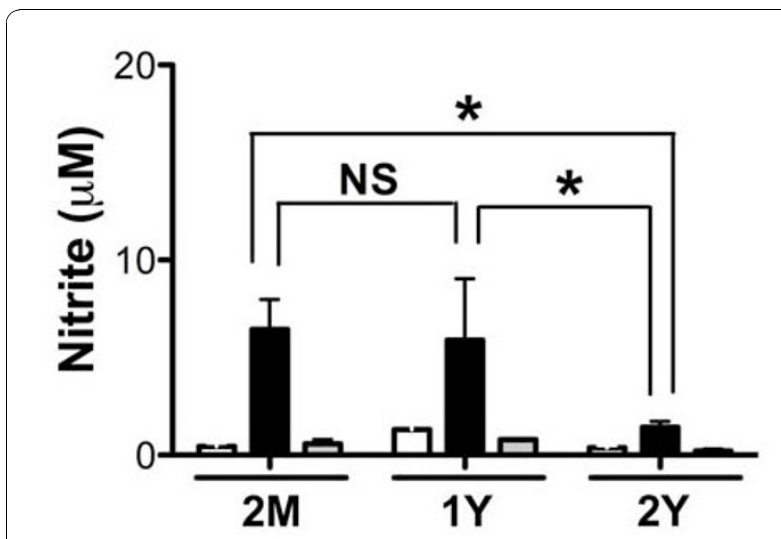

Figure 3 Nitric oxide levels from young and aged mouse BMM in response to $\mathbf{P g}$. NO present in cell culture supernatant fluids from mouse BMM of 2-months $(n=6), 1$-year $(n=3)$ and 2-years ( $n$ = 3) of age. BMM were cultured with Pg 381 (filled bars), Pg DPG3 (gray bars) at multiplicity of infection (MOI) of 100, or medium only control (open bars) for $24 \mathrm{~h}$. Secreted NO levels were inferred by measuring $\mu \mathrm{M}$ nitrite levels using Greiss reaction as previously described [36]. Asterisks indicate statistically significant $(P<0.05)$ as determined by Two way ANOVA with Bonferroni post-test analysis. NS = not significant.

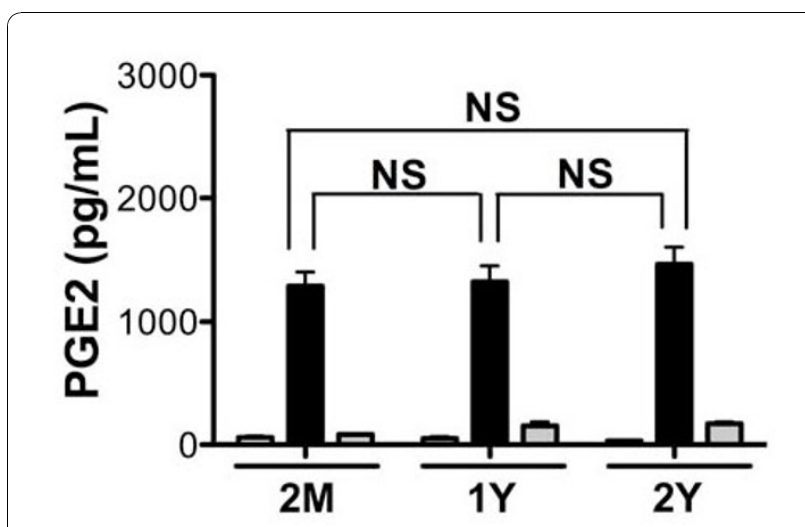

Figure 4 Prostaglandin E2 levels from young and aged mouse BMM in response to Pg. PGE2 present in cell culture supernatant fluids of mouse BMM from 2-months $(n=6), 1$-year $(n=3)$ and 2years $(n=3)$ of age. Cells were challenged with Pg 381 (filled bars), Pg DPG3 (gray bars) at multiplicity of infection (MOI) of 100, or medium only control (open bars) for $24 \mathrm{~h}$. PGE2 levels were measured by ELISA and the data presented as $\mathrm{pg} / \mathrm{mL}$ mean \pm standard error of the mean. Statistically was determined by Two way ANOVA with Bonferroni post-test analysis. NS = not significant.

induced robust expression of PGE2 in BMM from all age groups in comparison to unchallenged BMM. Levels of Pg-elicited PGE2 were similar among the age groups (Figure 4). These results indicate that Pg elicits robust expression of PGE2 from BMM independent of age.

As epidemiological data support that incidence of periodontal disease increases with age [18,19], and our data using wild type Pg indicated that BMM from aged mice displayed an overall trend of reduced ability to produce immune mediators as compared to that of young mice. We speculated that one possibility for the increased incidence of periodontal disease in aged populations may reflect the reduced function of immune response and an attenuated strain of Pg can induce immune response similar to a virulent $\mathrm{Pg}$ strain. To test this, we challenged BMM with wild type Pg 381 and a genetically attenuated mutant Pg strain that lacks major fimbriae, Pg DPG3 [45]. Major fimbriae are involved in Pg binding to cells $[46,47]$. This mutation has identified roles for Pg major fimbriae in stimulation of cytokines and chemokines from cells $[23,48]$, and oral bone loss [49]. This attenuated organism did not stimulate expression of any of the cytokines measured from young or aged BMM as robustly as wild type strain, Pg 381 (Figure 1A, B, C and 1D). Unexpectedly, we observed that despite the mutation, Pg DPG3 did induce a mild TNF- $\alpha$ response as compared to unchallenged control that occurred independent of age (Figure 1A). Focusing on chemokine expression, we observed that Pg DPG3 stimulated BMM also to produce MIP- $1 \alpha$ as compared with unchallenged control, like TNF- $\alpha$, these levels were 
significantly less than that observed with wild type $\mathrm{Pg}$ challenge (Figure 2C). KC, MCP-1, and RANTES production by BMM in response to Pg DPG3 challenge was not evident and levels of these mediators resembled the unchallenged controls (Figure 2A, B and 2D). Similarly Pg DPG3 failed to elicit NO and PGE2 production by BMM (Figure 3 and 4). These results collectively indicate that BMM exhibit a deprived innate immune response to an attenuated Pg mutant, suggesting, at least under these conditions, that aging does not contribute to BMM mounting vigorous immune responses to attenuated Pg similar to the wild type Pg 381.

\section{Discussion}

Periodontal disease is increasingly more common in adults as they age, suggesting that aging influences periodontal disease $[18,19,50,51]$. Despite this clear epidemiological connection, the mechanisms underlying aging and increased incidence/progression of periodontal disease are poorly understood; however, inflammatory response contributes significantly to periodontitis-associated tissue destruction. In the present study we examined the innate immune responses of BMM from 2-months (young), 1-year and 2-years (aged) mice in response to Pg 381 and an attenuated mutant Pg DPG3 in vitro. By measuring levels of cytokines, chemokines and other innate immune mediators in culture supernatant fluids from these cells in response to Pg challenge, despite some mediators, it is clear that BMM from aged mice display a reduced response to Pg 381 (Figure 1, 2, 3 and 4). It is evident from our data that BMM respond less vigorously to the attenuated mutant Pg DPG3 compared to Pg 381, and this occurred independent of age. This data indicate that major fimbriae is involved in Pgelicited innate immune response of murine BMM (Figure 1, 2, 3 and 4) and that attenuated Pg strain responded similar manner to the BMM independent of age. Together these data support that aging contributes to attenuated expression of cytokine, chemokine and other innate immune response mediators by murine $\mathrm{BMM}$ to Pg challenge in vitro. From these results, focusing on expression profiles of a limited, but highly relevant set of markers, as well as using only one cell type (BMM), it suggest that immunological senescence may participate in limiting host response to periodontal pathogen $\mathrm{Pg}$ and thus compromise immune function with age. These data are in agreement with the clinical observation that susceptibility to periodontal disease increases with age [52,53].

Recently it has been shown that macrophages from aged mice exhibit reduced production of cytokines to bacterial antigens including LPS and polysaccharide as compared to macrophages from young mice $[54,55]$. It is not completely understood the reason behind age dependent reduction in macrophage function; however, TLR expression is reduced on macrophages from old mice as compared with young, and thus may be responsible for the reduced cytokine levels expressed by macrophages from aged mice $[5,56]$. Although we did not define TLR expression on our macrophage population, it is possible that a TLR-dependent mechanism may be involved in host response to Pg. Indeed, both TLR2 and TLR4 have been implicated in recognition of live Pg [57] and several of its antigens including LPS and major fimbriae $[17,58]$ albeit in cells from young mice. Another potential mechanism that could be at bacterial advantage in aged populations is increased survival of pathogenic microorganisms in aged mice in comparison with young group [59,60]. A recent study using peritoneal macrophages from BALB/c mice showed no differences in the levels of either IL- $1 \beta$ or TNF- $\alpha$ proteins between macrophages of young (8-10 weeks) and aged ( $\geq 18$ months) groups in response to Pg; moreover, measured levels of IL-6 were significantly reduced in the aged group compared with young group [61]. However there was no significant difference in the transcript levels of these genes between macrophages from young and aged mice. Similar levels of secreted nitrite were also observed between peritoneal macrophages of young and old mice, cultured with Pg [61]. Several of our findings in the current study differ from those observed previously for host response of young and aged macrophages to Pg. In the present study, we measured significantly reduced levels of TNF- $\alpha$, and nitrite secreted from BMM of the aged (2-years) group as compared to the young group (2-months); whereas, Liang et al. [61] observed no significant difference in the levels of these molecules. Molecules where expression profiles were in agreement between our current study and this previous study [61] includes IL-6, which was reduced in aged macrophages, and IL- $1 \beta$ were no difference in expression between young and aged was observed. Although we do not understand why our data differ based on statistical interpretations from that of the previous study, clearly differences in experimental design between these two studies might have contributed. We employed C57BL/6 mice, whereas Liang et al. [61] used BALB/c mice. In addition, we employed Pg strain 381 while the previous study focused on Pg strain 33277.

Indeed, the choice of both mouse and Pg strains used may play importantly in the magnitude of the final measurements obtained, as it has been reported that these two variables can contribute substantially to data outcomes [62-64]. Regardless of the statistical interpretation, our results support the overall assessment of the study by Liang et al. [61] that aging leads to reduction in macrophage function in response to Pg. Observations 
from present study identify that BMM from aged mice respond to Pg challenge with reduction in key sets of immune mediators, as compared with BMM obtained from young mice.

In conclusion, our data from BMM of young and aged mice provides evidence of attenuated innate immune mediator expression to Pg challenge and suggest that immunological senescence is an important feature of the aging process that influences host response to periodontal pathogens. Further studies are clearly necessary to identify and better characterize the mechanisms underlying reduced immunological response of aged population to bacteria such as Pg in the context of periodontal disease pathogenesis.

\section{Abbreviations}

BMM: mouse bone marrow derived macrophages; IL: interleukin; KC: neutrophil chemoattractant or CXCL1; M-CSF: macrophage colony stimulating factor; MCP-1: monocyte chemotactic protein-1; MIP-1 $\alpha$ : macrophage inflammatory protein-1alpha; MOl: multiplicity of infection; NO: nitric oxide; Pg: Porphyromonas gingivalis; PGE2: prostaglandin E2; RANTES: regulated upon activation normal T cell expressed and secreted; TLRs: toll like receptors; TNF- $\alpha$ : tumor necrosis factor alpha.

\section{Acknowledgements}

This work was supported through PHS grant DE 018318 to FCG. Authors would like to thank Dr. Nasi Huang for his help with mouse bone marrow isolation.

\section{Author details}

'Department of Medicine, Section of Infectious Diseases, Boston University School of Medicine, Boston, Massachusetts 02118, USA. ${ }^{2}$ Department of Periodontology and Oral Biology, Boston University Henry M. Goldman School of Dental Medicine, Boston, Massachusetts 02118, USA.

\section{Authors' contributions}

YBS and FCG designed experiments, YBS performed experimentation, data analysis and preparation of manuscript were performed by YBS, AK, and FCG. All authors have read and approved the final manuscript.

\section{Competing interests}

The authors declare that they have no competing interests.

Received: 20 September 2010 Accepted: 29 November 2010 Published: 29 November 2010

\section{References}

1. Gavazzi G, Krause KH: Ageing and infection. Lancet Infect Dis 2002, 2:659-666.

2. Castle SC: Clinical relevance of age-related immune dysfunction. Clin Infect Dis 2000, 31:578-585.

3. Sambhara S, Kurichh A, Miranda R, James O, Underdown B, Klein M, Tartaglia J, Burt D: Severe impairment of primary but not memory responses to influenza viral antigens in aged mice: costimulation in vivo partially reverses impaired primary immune responses. Cell Immunol 2001, 210:1-4.

4. Hsu HC, Zhou T, Shi J, Yang PA, Liu D, Zhang HG, Bluethmann H, Mountz JD: Aged mice exhibit in vivo defective peripheral clonal deletion of $\mathrm{D}(\mathrm{b}) / \mathrm{H}-\mathrm{Y}$ reactive CD8(+) T cells. Mech Ageing Dev 2001, 122:305-326.

5. Renshaw M, Rockwell J, Engleman C, Gewirtz A, Katz J, Sambhara S: Cutting edge: impaired Toll-like receptor expression and function in aging. $J$ Immunol 2002, 169:4697-4701.

6. Akira S, Takeda K, Kaisho T: Toll-like receptors: critical proteins linking innate and acquired immunity. Nat Immunol 2001, 2:675-680.
7. Opal SM, Girard TD, Ely EW: The immunopathogenesis of sepsis in elderly patients. Clin Infect Dis 2005, 41(Suppl 7):S504-512.

8. Williams RC: Periodontal disease. N Engl J Med 1990, 322:373-382.

9. Slots J, Ting M: Actinobacillus actinomycetemcomitans and Porphyromonas gingivalis in human periodontal disease: occurrence and treatment. Periodontol 2000 1999, 20:82-121.

10. Socransky SS, Haffajee AD, Cugini MA, Smith C, Kent RL Jr: Microbial complexes in subgingival plaque. J Clin Periodontol 1998, 25:134-144.

11. Grenier D, Mayrand D: Periodontitis as an ecological imbalance. Wymondham, Norfolk, United Kingdom: Horizon Scientific Press; 2000.

12. Kadowaki T, Nakayama K, Okamoto K, Abe N, Baba A, Shi Y, Ratnayake DB, Yamamoto K: Porphyromonas gingivalis proteinases as virulence determinants in progression of periodontal diseases. J Biochem 2000, 128:153-159.

13. Bainbridge BW, Coats SR, Darveau RP: Porphyromonas gingivalis lipopolysaccharide displays functionally diverse interactions with the innate host defense system. Ann Periodontol 2002, 7:29-37.

14. Laine ML, van Winkelhoff AJ: Virulence of six capsular serotypes of Porphyromonas gingivalis in a mouse model. Oral Microbiol Immunol 1998, 13:322-325.

15. Davey M, Liu X, Ukai T, Jain V, Gudino C, Gibson FC, Golenbock D, Visintin A, Genco CA: Bacterial fimbriae stimulate proinflammatory activation in the endothelium through distinct TLRs. J Immunol 2008, 180:2187-2195.

16. Offenbacher S, Odle BM, Van Dyke TE: The use of crevicular fluid prostaglandin E2 levels as a predictor of periodontal attachment loss. $J$ Periodontal Res 1986, 21:101-112.

17. Hiramine $H$, Watanabe $K$, Hamada N, Umemoto T: Porphyromonas gingivalis $67-\mathrm{kDa}$ fimbriae induced cytokine production and osteoclast differentiation utilizing TLR2. FEMS Microbiol Lett 2003, 229:49-55.

18. Tanaka S, Murakami Y, Ogiwara T, Shoji M, Seto K, Nagasaki M, Fujisawa S: Frequency of reactivity for Porphyromonas gingivalis and Prevotella spp. In supra- and subgingival plaques, and periodontal clinical parameters according to subject age. J Periodontol 2002, 73:877-885.

19. Papapanou PN, Wennstrom $J L$, Grondahl K: Periodontal status in relation to age and tooth type. A cross-sectional radiographic study. I Clin Periodontol 1988, 15:469-478.

20. Baer MT, Huang N, Gibson FC: Scavenger receptor A is expressed by macrophages in response to Porphyromonas gingivalis, and participates in TNF-alpha expression. Oral Microbiol Immunol 2009, 24:456-463.

21. Jandik KA, Belanger M, Low SL, Dorn BR, Yang MC, Progulske-Fox A: Invasive differences among Porphyromonas gingivalis strains from healthy and diseased periodontal sites. J Periodontal Res 2008, 43:524-530.

22. Tomida M, Yamamoto-Yamaguchi Y, Hozumi M: Purification of a factor inducing differentiation of mouse myeloid leukemic M1 cells from conditioned medium of mouse fibroblast L929 cells. J Biol Chem 1984, 259:10978-10982.

23. Chou HH, Yumoto H, Davey M, Takahashi Y, Miyamoto T, Gibson FC, Genco CA: Porphyromonas gingivalis fimbria-dependent activation of inflammatory genes in human aortic endothelial cells. Infect Immun 2005, 73:5367-5378.

24. Yumoto H, Chou HH, Takahashi Y, Davey M, Gibson FC, Genco CA: Sensitization of human aortic endothelial cells to lipopolysaccharide via regulation of Toll-like receptor 4 by bacterial fimbria-dependent invasion. Infect Immun 2005, 73:8050-8059.

25. Gibson $\mathrm{FC}$, Hong $\mathrm{C}$, Chou HH, Yumoto H, Chen J, Lien E, Wong J, Genco CA: Innate immune recognition of invasive bacteria accelerates atherosclerosis in apolipoprotein E-deficient mice. Circulation 2004, 109:2801-2806.

26. Seymour GJ, Gemmell E: Cytokines in periodontal disease: where to from here? Acta Odontol Scand 2001, 59:167-173.

27. Gamonal J, Acevedo A, Bascones A, Jorge O, Silva A: Levels of interleukin-1 beta, -8 , and -10 and RANTES in gingival crevicular fluid and cell populations in adult periodontitis patients and the effect of periodontal treatment. J Periodontol 2000, 71:1535-1545.

28. Ukai T, Yumoto H, Gibson FC, Genco CA: Macrophage-elicited osteoclastogenesis in response to bacterial stimulation requires Toll-like receptor 2-dependent tumor necrosis factor-alpha production. Infect Immun 2008, 76:812-819.

29. d'Empaire G, Baer MT, Gibson FC: The K1 serotype capsular polysaccharide of Porphyromonas gingivalis elicits chemokine production 
from murine macrophages that facilitates cell migration. Infect Immun 2006, 74:6236-6243.

30. Zhou Q, Desta T, Fenton M, Graves DT, Amar S: Cytokine profiling of macrophages exposed to Porphyromonas gingivalis, its lipopolysaccharide, or its FimA protein. Infect Immun 2005, 73:935-943.

31. Lappin DF, MacLeod CP, Kerr A, Mitchell T, Kinane DF: Anti-inflammatory cytokine IL-10 and T cell cytokine profile in periodontitis granulation tissue. Clin Exp Immunol 2001, 123:294-300.

32. Gemmell E, Grieco DA, Seymour GJ: Chemokine expression in Porphyromonas gingivalis-specific T-cell lines. Oral Microbiol Immunol 2000, 15:166-171.

33. Strieter RM, Standiford TJ, Huffnagle GB, Colletti LM, Lukacs NW, Kunkel SL: "The good, the bad, and the ugly." The role of chemokines in models of human disease. J Immunol 1996, 156:3583-3586.

34. Silva TA, Garlet GP, Fukada SY, Silva JS, Cunha FQ: Chemokines in oral inflammatory diseases: apical periodontitis and periodontal disease. $J$ Dent Res 2007, 86:306-319.

35. Hosokawa Y, Nakanishi T, Yamaguchi D, Takahashi K, Yumoto H, Ozaki K Matsuo T: Macrophage inflammatory protein 3alpha-CC chemokine receptor 6 interactions play an important role in CD4+ T-cell accumulation in periodontal diseased tissue. Clin Exp Immunol 2002, 128:548-554.

36. Shapira L, Frolov I, Halabi A, Ben-Nathan D: Experimental stress suppresses recruitment of macrophages but enhanced their $P$. gingivalis LPSstimulated secretion of nitric oxide. J Periodontol 2000, 71:476-481.

37. Antonini JM, Roberts JR, Clarke RW, Yang HM, Barger MW, Ma JY, Weissman DN: Effect of age on respiratory defense mechanisms: pulmonary bacterial clearance in Fischer 344 rats after intratracheal instillation of Listeria monocytogenes. Chest 2001, 120:240-249.

38. De Groote MA, Fang FC: NO inhibitions: antimicrobial properties of nitric oxide. Clin Infect Dis 1995, 21(Suppl 2):S162-165.

39. Allaker RP, Silva Mendez LS, Hardie JM, Benjamin N: Antimicrobial effect of acidified nitrite on periodontal bacteria. Oral Microbiol Immunol 2001, 16:253-256.

40. Gyurko R, Boustany G, Huang PL, Kantarci A, Van Dyke TE, Genco CA, Gibson FC: Mice lacking inducible nitric oxide synthase demonstrate impaired killing of Porphyromonas gingivalis. Infect Immun 2003, 71:4917-4924.

41. Hajishengallis G, Wang M, Bagby GJ, Nelson S: Importance of TLR2 in early innate immune response to acute pulmonary infection with Porphyromonas gingivalis in mice. J Immunol 2008, 181:4141-4149.

42. Alayan J, Ivanovski S, Gemmell E, Ford P, Hamlet S, Farah CS: Deficiency of iNOS contributes to Porphyromonas gingivalis-induced tissue damage. Oral Microbiol Immunol 2006, 21:360-365.

43. Scher JU, Pillinger MH: The anti-inflammatory effects of prostaglandins. J Investig Med 2009, 57:703-708.

44. Offenbacher S, Salvi GE: Induction of prostaglandin release from macrophages by bacterial endotoxin. Clin Infect Dis 1999, 28:505-513.

45. Hamada N, Watanabe K, Sasakawa C, Yoshikawa M, Yoshimura F, Umemoto T: Construction and characterization of a fimA mutant of Porphyromonas gingivalis. Infect Immun 1994, 62:1696-1704.

46. Khlgatian M, Nassar H, Chou HH, Gibson FC, Genco CA: Fimbria-dependent activation of cell adhesion molecule expression in Porphyromonas gingivalis-infected endothelial cells. Infect Immun 2002, 70:257-267.

47. Weinberg A, Belton CM, Park Y, Lamont RJ: Role of fimbriae in Porphyromonas gingivalis invasion of gingival epithelial cells. Infect Immun 1997, 65:313-316.

48. Nassar H, Chou HH, Khlgatian M, Gibson FC, Van Dyke TE, Genco CA: Role for fimbriae and lysine-specific cysteine proteinase gingipain $\mathrm{K}$ in expression of interleukin-8 and monocyte chemoattractant protein in Porphyromonas gingivalis-infected endothelial cells. Infect Immun 2002, 70:268-276.

49. Malek R, Fisher JG, Caleca A, Stinson M, van Oss CJ, Lee JY, Cho MI, Genco RJ, Evans RT, Dyer DW: Inactivation of the Porphyromonas gingivalis fimA gene blocks periodontal damage in gnotobiotic rats. $J$ Bacteriol 1994, 176:1052-1059.

50. Campisi G, Chiappelli M, De Martinis M, Franco V, Ginaldi L, Guiglia R, Licastro F, Lio D: Pathophysiology of age-related diseases. Immun Ageing 2009, 6:12.
51. Mouton C, Hammond PG, Slots J, Genco RJ: Serum antibodies to oral Bacteroides asaccharolyticus [Bacteroides gingivalis): relationship to age and periondontal disease. Infect Immun 1981, 31:182-192.

52. Van der Velden U: Effect of age on the periodontium. $J$ Clin Periodontol 1984, 11:281-294.

53. Russell AL: Epidemology of periodontal disease. Int Dent J 1967, 17:282-296.

54. Chelvarajan RL, Liu Y, Popa D, Getchell ML, Getchell TV, Stromberg AJ, Bondada S: Molecular basis of age-associated cytokine dysregulation in LPS-stimulated macrophages. J Leukoc Biol 2006, 79:1314-1327.

55. Chelvarajan RL, Collins SM, Van Willigen JM, Bondada S: The unresponsiveness of aged mice to polysaccharide antigens is a result of a defect in macrophage function. $J$ Leukoc Biol 2005, 77:503-512.

56. van Duin D, Shaw AC: Toll-like receptors in older adults. J Am Geriatr Soc 2007, 55:1438-1444.

57. Bagaitkar J, Demuth DR, Daep CA, Renaud DE, Pierce DL, Scott DA: Tobacco upregulates $P$. gingivalis fimbrial proteins which induce TLR2 hyposensitivity. PLoS One 5:e9323.

58. Ogawa T, Asai Y, Hashimoto M, Takeuchi O, Kurita T, Yoshikai Y, Miyake K, Akira S: Cell activation by Porphyromonas gingivalis lipid A molecule through Toll-like receptor 4- and myeloid differentiation factor 88dependent signaling pathway. Int Immunol 2002, 14:1325-1332.

59. Kernacki KA, Barrett RP, McClellan SA, Hazlett LD: Aging and PMN response to $P$. aeruginosa infection. Invest Ophthalmol Vis Sci 2000, 41:3019-3025.

60. Orme IM: Aging and immunity to tuberculosis: increased susceptibility of old mice reflects a decreased capacity to generate mediator $T$ lymphocytes. J Immunol 1987, 138:4414-4418.

61. Liang S, Domon H, Hosur KB, Wang M, Hajishengallis G: Age-related alterations in innate immune receptor expression and ability of macrophages to respond to pathogen challenge in vitro. Mech Ageing Dev 2009, 130:538-546.

62. Baker PJ, Dixon M, Roopenian DC: Genetic control of susceptibility to Porphyromonas gingivalis-induced alveolar bone loss in mice. Infect Immun 2000, 68:5864-5868.

63. Baker PJ, Dixon M, Evans RT, Roopenian DC: Heterogeneity of Porphyromonas gingivalis strains in the induction of alveolar bone loss in mice. Oral Microbiol Immunol 2000, 15:27-32.

64. Shapira L, Champagne C, Van Dyke TE, Amar S: Strain-dependent activation of monocytes and inflammatory macrophages by lipopolysaccharide of Porphyromonas gingivalis. Infect Immun 1998, 66:2736-2742.

doi:10.1186/1742-4933-7-15

Cite this article as: Shaik-Dasthagirisaheb et al: Immune response of macrophages from young and aged mice to the oral pathogenic bacterium Porphyromonas gingivalis. Immunity \& Ageing 2010 7:15.

\section{Submit your next manuscript to BioMed Central and take full advantage of:}

- Convenient online submission

- Thorough peer review

- No space constraints or color figure charges

- Immediate publication on acceptance

- Inclusion in PubMed, CAS, Scopus and Google Scholar

- Research which is freely available for redistribution

Submit your manuscript at www.biomedcentral.com/submit
C Biomed Central 